\title{
ESTABLISHING RELATIONSHIP BETWEEN CBR WITH DIFFERENT SOIL PROPERTIES
}

\author{
P.G. Rakaraddi ${ }^{1}$, Vijay Gomarsi ${ }^{2}$ \\ ${ }^{1}$ Professor, Department of civil engineering, Basaveshwar Engineering College, Bagalkot, Karnataka, India. \\ ${ }^{2}$ Post graduate student, geotechnical engineering, Department of civil engineering, Basaveshwar Engineering \\ College, Bagalkot, Karnataka, India.
}

\begin{abstract}
In the flexible pavements sub-grade is considered to be an ideal layer to resist wheel load and its CBR value is considered as the strength measuring parameter. Conducting CBR test is an expensive and time consuming test, moreover it is very difficult to mould the sample at a desired in-situ density in the laboratory. Further, if the available soil is of poor quality, suitable additives are mixed with soil and resulting strength of soil is assessed by CBR value which is cumbersome. To overcome these problems, the other methods such as regression based models (simple \& multiple) are used in this study. The soil properties like liquid limit, plastic limit, plasticity index, optimum moisture content, maximum dry density and percentage fineness of the soil (passing 75micron sieve) are determined for the soil collected from different areas of Bagalkot district and the models are developed for correlating soaked CBR value.
\end{abstract}

Keywords: CBR, regression models, liquid limit, plastic limit, plasticity index, optimum moisture content and maximum dry density.

\section{INTRODUCTION}

Roads are necessary for transportation and economic development of the country. Most of the road network in the country is consisting of flexible pavement. Flexible pavement consists of different layers such as sub-grade, subbase, base course and surface layer. Sub-grade is the bottom most layer. Design and performance of flexible pavement mainly depends on the strength of sub-grade material. The load from the pavement surface is ultimately transferred to sub-grade and to the sub-base. The sub-grade is designed such that the stress transferred should not exceed elastic limit. Hence, the suitability and stability of sub-grade material is evaluated before construction of pavement. Soaked California bearing ratio $(C B R)$ value $(\%)$ is considered as strength parameter in design of sub-grade.

The thickness of sub-grade is mainly depends on $C B R$ value, if the $C B R$ value is higher, then the designed thickness of the sub-grade is thinner and vice versa. The soaked $C B R$ test requires large quantity of soil sample and the soil is remolded to its maximum dry density $(M D D)$ and time consuming. Therefore it is very difficult to carry out to entire stretch of road in a short duration and leads to serious delay in the project and increases its cost. To overcome this problem a simple and less time consuming method is necessary by correlating soaked CBR value with easily determining soil parameters.

Cohesive soil $C B R$ value is correlated with plasticity and liquidity index (Black: 1962), liquid limit and gradation characteristics of soil (Vinod and Cletus; 2008). Pradeep Muley and Jain (2013) developed a correlation to predict $C B R$ of stone dust mixed poor soil. Roy et.al; 2010 and
Hakari and Nadgauda; 2013 correlated the $C B R$ value by using presumptive design chart and Nomography as per IRC SP: 37-2007. Patel et.al (2010), Venkatasubramanian and Dhinakaran (2011), Ramasunnarao and Siva Sankar (2013), Akshay (2013), and Dilip Kumar Tulukdar (2014) had developed multiple liner regression analysis models (MLRA) for correlating $C B R$ with index properties of soil. In the present study soaked $C B R$ is correlated using simple correlation and MLRA with the properties of soil like liquid limit, plastic limit, and plasticity index, optimum moisture content $(O M C)$, maximum dry density $(M D D)$ and percentage fineness.

\section{METHODOLOGY}

\subsection{Simple Relation}

To establish relation between soaked $C B R$ and different soil properties, graphs are plotted with $C B R$ against different soil parameters and suitable trend line is drawn with higher correlation coefficient. Correlation quantifies the degree to which dependent and independent variables are related. Linear regression quantifies goodness of fit with $\mathrm{R}^{2}$ value. $\mathrm{R}^{2}$ value provides a measure of how well future outcomes are likely to be predicted by the model. Any correlation with $R^{2}$ value more than 0.80 will be viewed as a best fit.

\subsection{Multiple Linear Regression Analysis (MLRA)}

To develop the models of multiple linear regression analysis soaked $C B R$ value is considered as independent variable and soil properties such as Gravel (G), Fines (F), Sand(S), $L L$, $P L, M D D$ and $O M C$ are considered as the dependent variables. 
MLRA has been carried out by considering soaked $C B R$ value as the independent variable and the rest of soil properties as dependent variables. MLRA can be carried out using standard statistical software like data analysis tool bar of Microsoft Excel in order to derive the relationship statistically.

$$
\text { CBRs }=\mathrm{f}(\mathrm{F}, \mathrm{S}, \mathrm{G}, \mathrm{LL}, \mathrm{PL}, \mathrm{MDD}, \mathrm{OMC})
$$

The objective function for applying genetic algorithm in this research study will be formulated as follows:

$Y$ is directly proportional to the variables $x_{1}, x_{2}, x_{3}, x_{4} \& x_{n}$. So, the equation created will be

$$
y=b_{0}+b_{1} x_{1}+b_{2} x_{2}+b_{3} x_{3}+b_{4} x_{4} \ldots \ldots \ldots \ldots \ldots+b_{n} x_{n}
$$

Where,

$y=$ California Bearing Ratio (\%),

\section{RESULTS AND DISCUSSION}

The results obtained from the tests are exclusively given in table 1 .

\begin{tabular}{|c|c|c|c|c|c|c|c|c|}
\hline \multirow{2}{*}{ SI No. } & \multirow{2}{*}{ Description } & \multicolumn{7}{|c|}{ Sample No } \\
\hline & & 1 & 2 & 3 & 4 & 5 & 6 & 7 \\
\hline 1 & Gravel (\%) & 27.73 & 1.86 & 0.00 & 2.00 & 5.23 & 1.50 & 25.92 \\
\hline 2 & Coarse Sand (\%) & 36.55 & 0.76 & 5.30 & 8.00 & 12.64 & 3.08 & 6.00 \\
\hline 3 & Medium Sand (\%) & 7.25 & 30.00 & 6.62 & 4.00 & 25.10 & 3.47 & 5.08 \\
\hline 4 & Fine Sand (\%) & 8.51 & 19.69 & 2.96 & 15.73 & 14.98 & 1.90 & 8.20 \\
\hline 5 & Fines (silt and clay) (\%) & 19.96 & 47.69 & 85.12 & 70.27 & 42.05 & 90.04 & 54.80 \\
\hline 6 & LL (\%) & 29.00 & 43.50 & 78.00 & 72.50 & 47.00 & 37.00 & 59.00 \\
\hline 7 & PL (\%) & 18.00 & 18.14 & 43.00 & 28.00 & 21.50 & 16.14 & 22.00 \\
\hline 8 & PI $(\%)$ & 11.00 & 25.36 & 35.00 & 44.50 & 25.50 & 20.86 & 37.00 \\
\hline 9 & OMC (\%) & 12.60 & 17.00 & 29.80 & 28.60 & 20.00 & 16.20 & 25.00 \\
\hline 10 & MDD (gm/cc) & 2.20 & 1.70 & 1.42 & 1.45 & 1.66 & 1.85 & 1.54 \\
\hline 11 & Specific gravity & 2.59 & 2.63 & 2.82 & 2.80 & 2.50 & 2.69 & 2.80 \\
\hline 12 & Soaked CBR (\%) & 9.2 & 3.33 & 0.48 & 1.33 & 3.16 & 8.82 & 2.26 \\
\hline
\end{tabular}

Table 1 Properties of soil samples

\subsection{Relation between Soaked CBR and Soil Properties}

In fig 1-4 the relationship between $C B R$ and different soil properties are plotted and mathematical equation is generated.

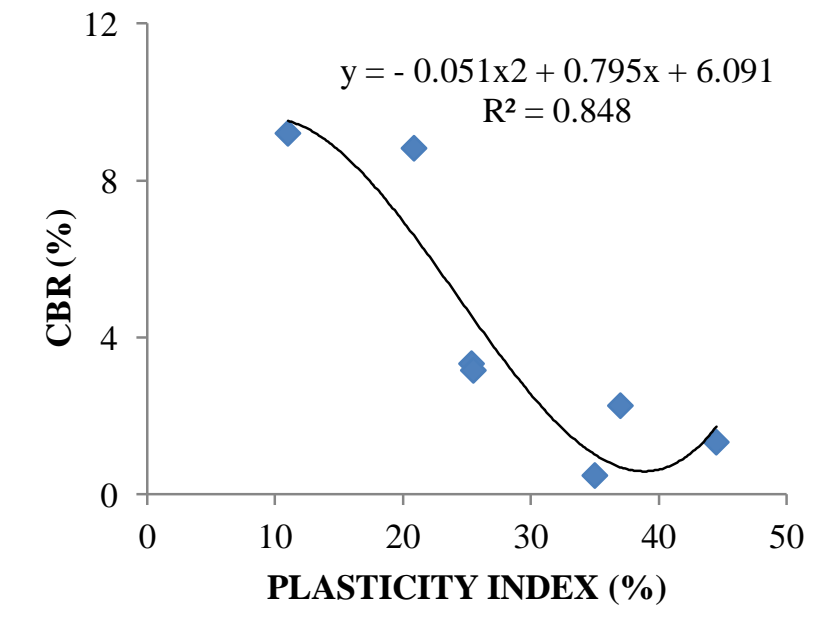

Fig-1 Relation between CBR with Plasticity index $b_{1}, b_{3}, b_{4}, b_{n}=$ constants
$x_{1}, x_{2}, x_{3}, x_{4}, x_{n}=$ soil property considered for analysis.

The values of above constants will be solved using MLRA in the data analysis toolbar a built-in add-in for Microsoft Excel. So by inputting the values of $C B R$, liquid limit, plasticity index, optimum moisture content and fine fractions we can obtain the values for the constants.

\section{MATERIALS}

Different soil samples were collected from various locations of Bagalkot district, Karnataka. The $C B R$ value, optimum moisture content, maximum dry density, particle size distribution, liquid limit, plastic limit, shrinkage limit, plasticity index are determined in the laboratory. All these tests were performed according to IS code IS 2720 Part I - VI and XVI specification. 
The variation between soaked $C B R$ and plasticity index is shown in fig 1 and the suitable trend line is third degree polynomial equation $C B R=-0.051 \mathrm{PI}^{2}+0.795 \mathrm{PI}+6.09 \mathrm{PI}$.

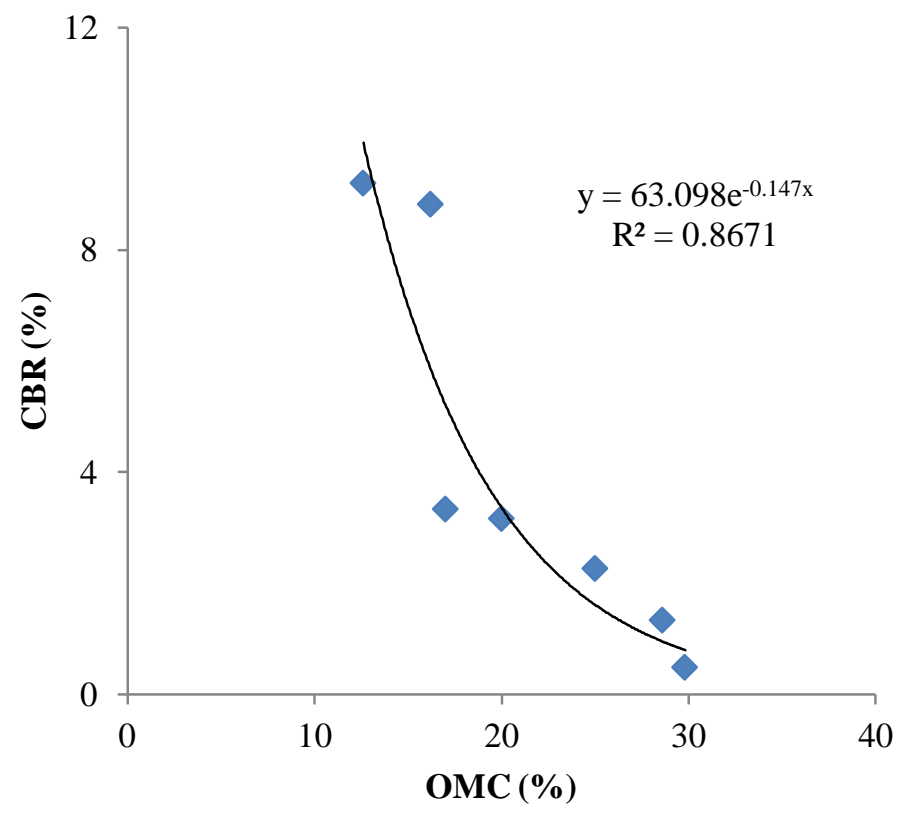

Fig-2: Relation between CBR with OMC

The fig 2 shows the trend of soaked $C B R$ with optimum moisture content. The suitable trend line is exponential equation $C B R=$ $63.09 \mathrm{e}^{-0.14 \mathrm{OMC}}$

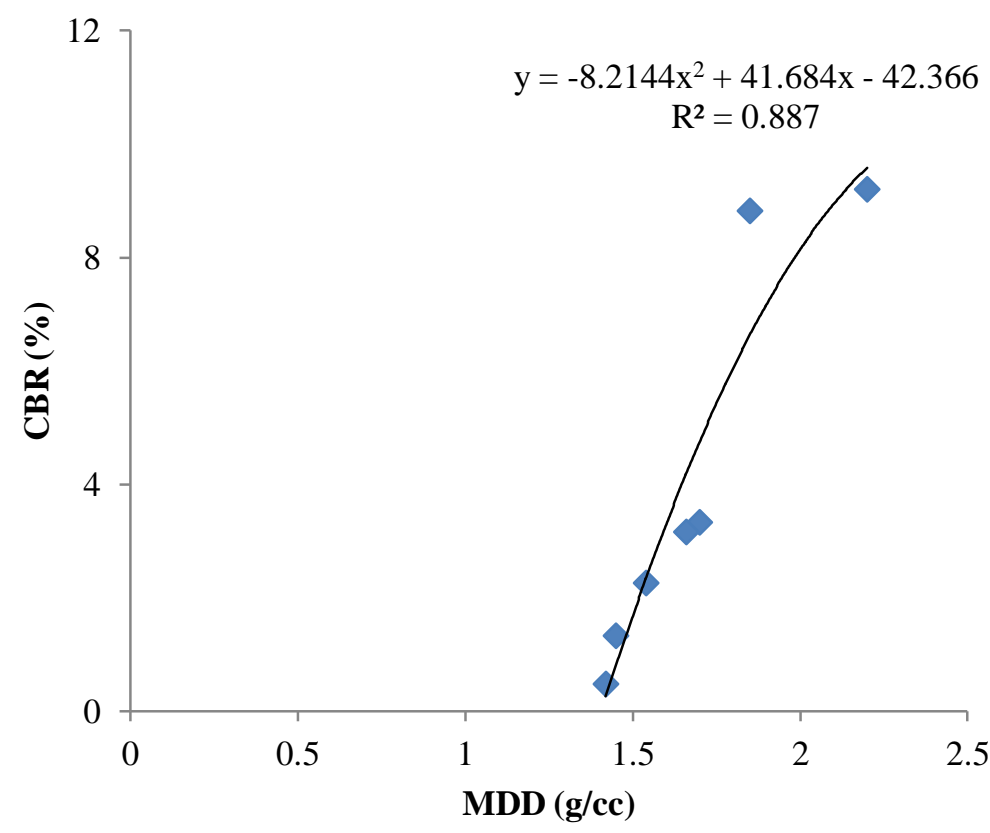

Fig-3: Relation between CBR with MDD

In fig 3, $C B R$ variation with $M D D$ is shown. Correlation between soaked $C B R$ and maximum dry density is obtained in fig -3 the suitable trend line is second degree polynomial. $C B R=-8.214 \mathrm{MDD}^{2}+41.68 \mathrm{MDD}-42.36$. 


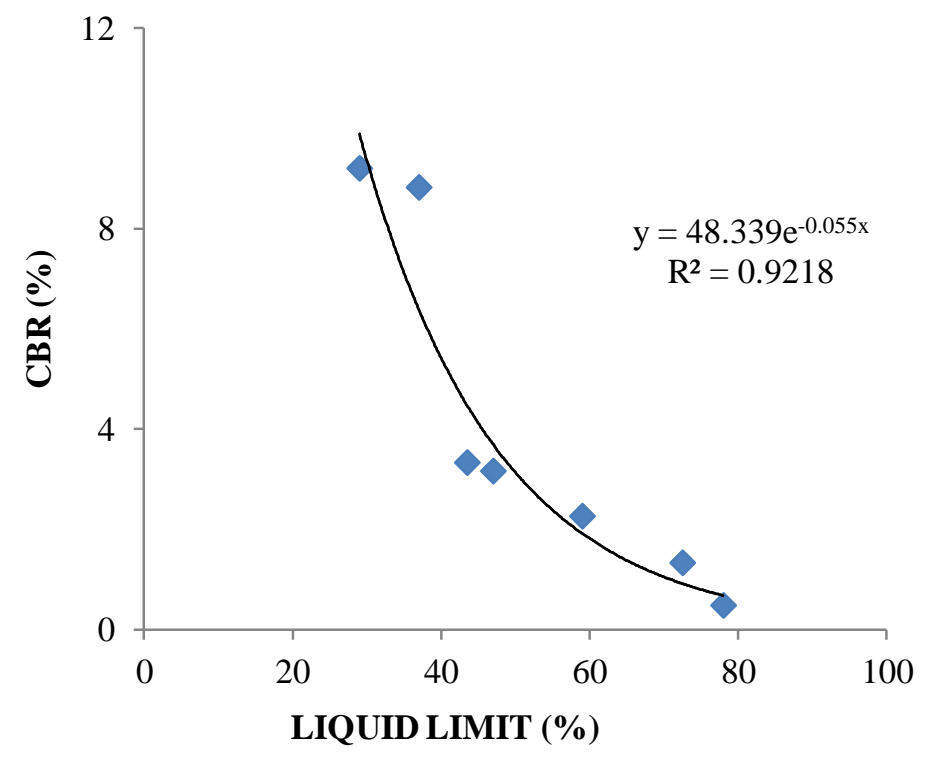

Fig-4: Relation between CBR with Liquid limit

Variation of liquid and $C B R$ is shown in fig 4 . The best fit trend line is an exponential equation

$C B R=48.33^{\mathrm{e}-0.05 \mathrm{LL}}$.

The coefficient of correlation of different curves plotted in fig 1-4 is given in table 2 .

Table 2: Coefficient of correlation for different soil parameters with $C B R$ value

\begin{tabular}{|l|l|l|}
\hline $\begin{array}{l}\text { Sl. } \\
\text { No }\end{array}$ & Correlation of $\boldsymbol{C B R}$ with & $\begin{array}{l}\text { Coefficient of correlation } \\
\left(\mathbf{R}^{\mathbf{2}}\right)\end{array}$ \\
\hline 1 & Plasticity index & 0.848 \\
\hline 2 & Optimum moisture content & 0.867 \\
\hline 3 & Maximum dry density & 0.887 \\
\hline 4 & Liquid limit & 0.921 \\
\hline
\end{tabular}

From table 2 soaked $C B R$ with respect to liquid limit has good correlation with exponential trend line have highest correlation coefficient of 0.921 whereas the minimum correlation coefficient of 0.848 is with plasticity index. As the fines increases optimum moisture content increases hence decrease in maximum dry density there by soaked $C B R$ value decreases.

\subsection{Multiple Linear Regression Analysis}

By correlating soaked $C B R$ with optimum moisture content and maximum dry density Mathematical equation is generated as given below.

$$
\mathrm{CBR}=-0.26052 \mathrm{OMC}+5.717093 \mathrm{MDD} \quad \mathrm{R}^{2}=0.940------(1)
$$

Fig- 5 is plotted with respect to laboratory $C B R$ value obtained for different soil samples and predicted $C B R$ value (obtained from equation-1). 


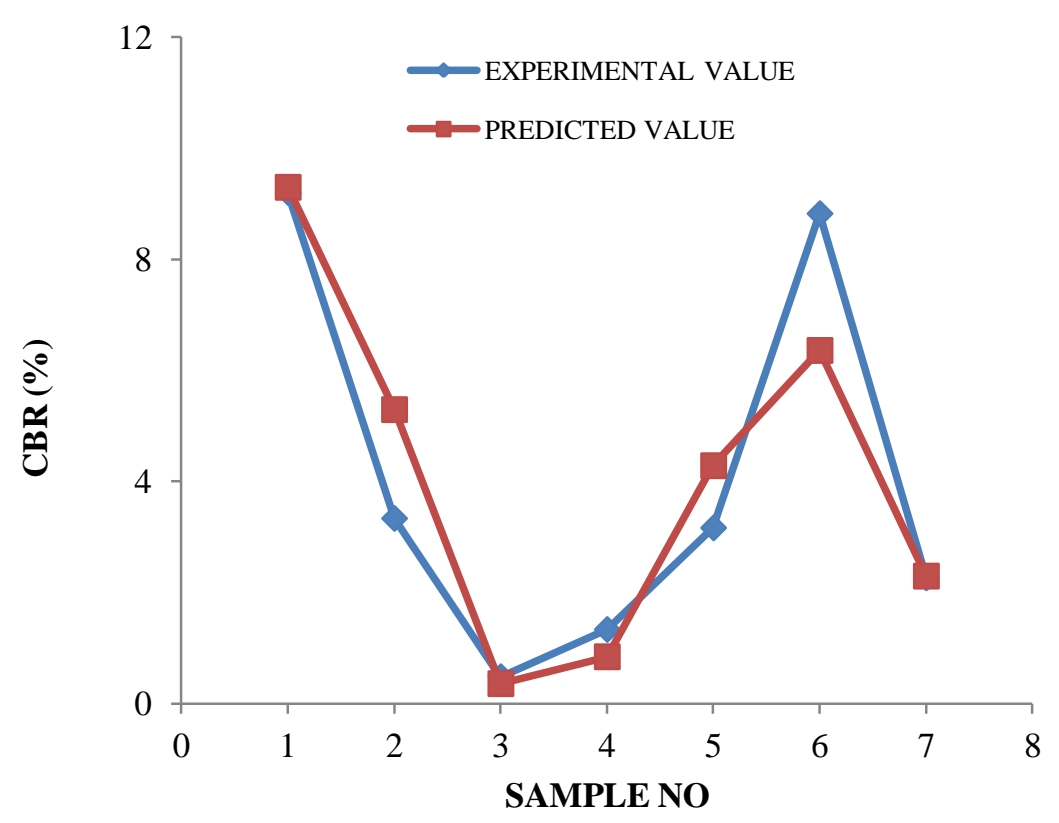

Fig-5: Predicted CBR OF Equation-1 and Laboratory CBR

By correlating soaked $C B R$ with Liquid limit, plastic limit, fines, and specific gravity Mathematical equation is generated as given below

$$
\mathrm{CBR}=-0.275 \mathrm{LL}+0.118 \mathrm{PL}+0.033 \mathrm{~F}+5.106 \mathrm{G} \quad \mathrm{R}^{2}=0.961--(2)
$$

Fig-6 is plotted with respect to laboratory CBR value and predicted CBR value (obtained from above equation-2)

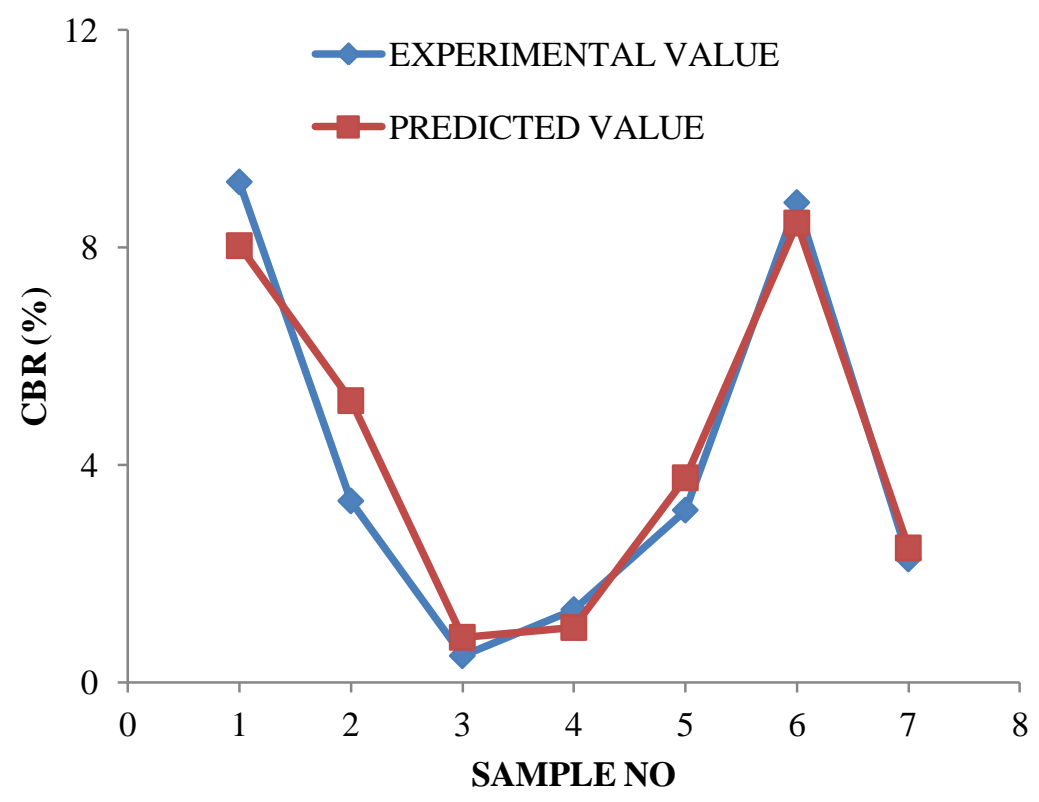

Fig-6: Predicted CBR OF Equation-2 and Laboratory CBR

By correlating the soaked $C B R$ value with percentage fineness, optimum moisture content, plasticity index and specific gravity, the mathematical equation is generated as given below

$$
\mathrm{CBR}=0.030 \mathrm{~F}-0.426 \mathrm{OMC}-0.117 \mathrm{PI}+5.471 \mathrm{G} \quad \mathrm{R}^{2}=0.951-(3)
$$


Fig-7 is plotted with respect to laboratory $C B R$ value and predicted $C B R$ value (obtained from equation -3 )

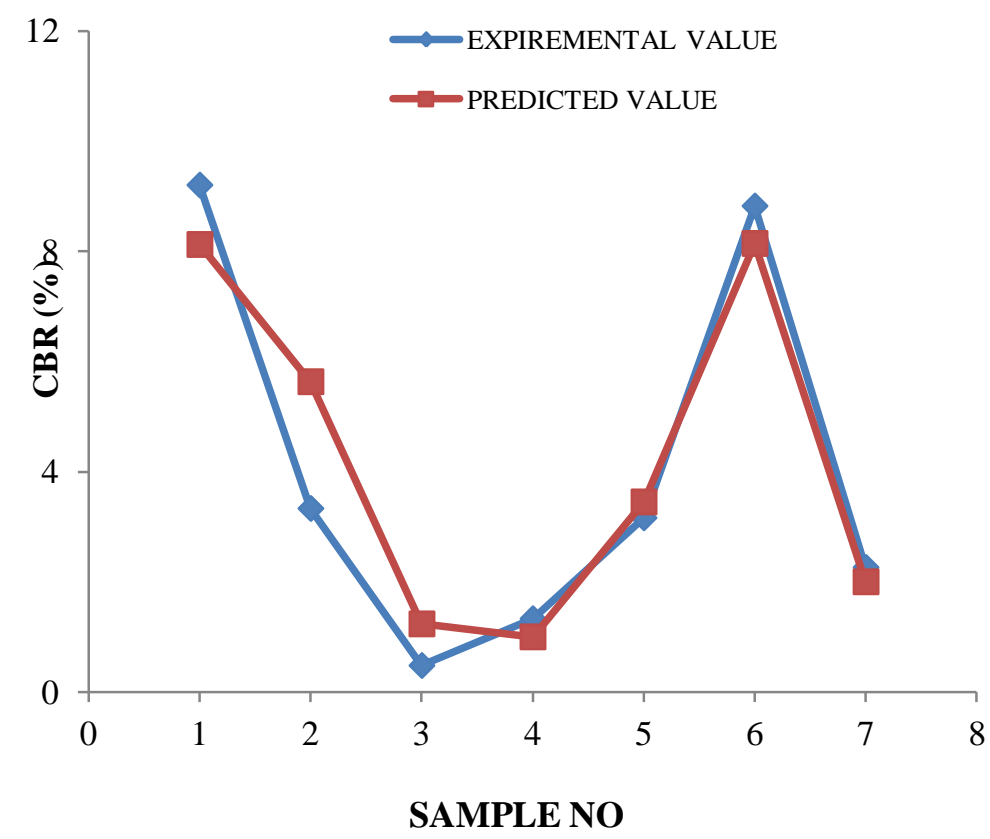

Fig 7: Predicted CBR OF Equation-3 and Laboratory CBR

By correlating soaked $C B R$ with optimum moisture content and specific gravity Mathematical equation is generated as given below

$$
\mathrm{CBR}=-0.557 \mathrm{OMC}+5.943 \mathrm{G} \quad \mathrm{R}^{2}=0.931
$$

Fig-8 is plotted with respect to laboratory CBR value and predicted CBR value (obtained from equation 4)

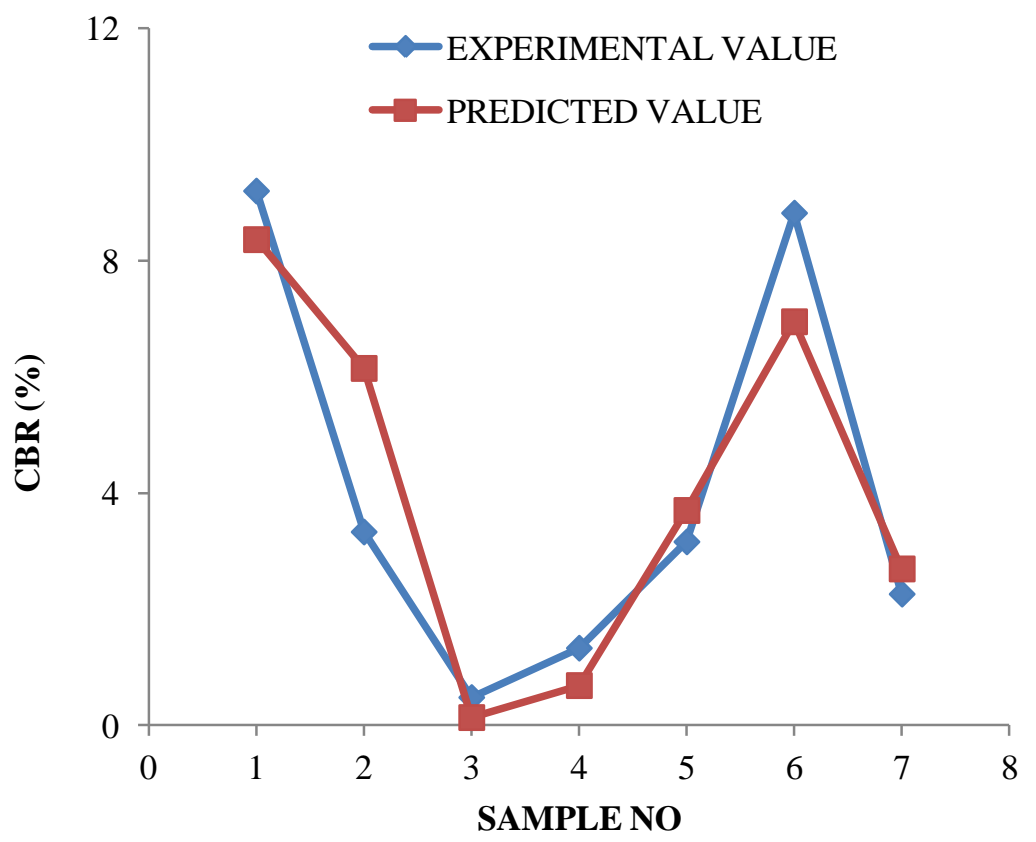

Fig-8: Predicted CBR OF Equation-4 and Laboratory CBR 


\section{CONCLUSION}

Based on above test results and discussions the following conclusions may be made

- From simple correlation method $C B R$ can be predicted by soil properties.

- Liquid limit is considered as higher priority for predicting soaked $C B R$ value followed by $O M C$, $M D D$ and $P I$ based on assessment factor $\mathrm{R}^{2}$.

- $\quad C B R$ correlated with liquid limit, plastic limit, fines and specific gravity equation generated is $\mathrm{CBR}=-$ $0.275 \mathrm{LL}+0.118 \mathrm{PL}+0.033 \mathrm{~F}+5.106 \mathrm{G}$ with $\mathrm{R}^{2}=0.961$ provides good value.

- Multiple linear regression analysis is better correlation method than simple correlation.

\section{REFERENCES}

[1]. IS: 2720 Part XVI (1980) IS: 9669, Laboratory determination of California bearing ratio (CBR) of soil, BIS, New Delhi.

[2]. Black, W.P.M. (1962). A Method of estimating the CBR of cohesive soils from plasticity data, Geotechnique, Vol.12, $271-272$.

[3]. Vinod, P. \& Cletus Reena, (2008), Prediction of lateritic soil using liquid limit and Gradation characteristics data, Highway Research Journal, Vol. No. 1, 89-98.

[4]. Roy T.K., Chattopadhyay B.C. and Roy S.K., (2006), Prediction of CBR for sub-grade of different materials from simple test., Proc. International Conference on 'Civil Engineering in the New Millennium - Opportunities and Challenges', BESUS, West Bengal, Vol.-III, pp.2091-2098.

[5]. U. D. Hakari, K.D.Nadagouda,(2013) Estimation and evaluation of California bearing ratio by indirect methods, Proceedings of Indian Geotechnical Conference December 22-24, Roorkee.

[6]. Patel, R. S. and Desai, M.D. (2010), CBR Predicted by index properties for alluvial soils of south Gujarat, Indian Geotechnical Conference, IIT Bombay, Proc. IGC, Vol. I, 79-82.

[7]. Venkatasubramanian.C, Dinakaran.G (2011), ANN model for predicting CBR from index properties of soil, International Journal of Civil and Structural Engineering, Vol. 2, No 2, 2011.

[8]. Ramasubbaroa, G.V., Siva Sankar, G.(2013), Predicting Soaked CBR Value Of Fine Grained Soil Using Index and Compaction Characteristics, Jordan Journal Of Civil Engineering, Vol 7, No-3.

[9]. Akashaya Kumar Sabat(2013), Prediction of CBR a soil Stabilized with Lime and Quarry Dust Using Artificial Neural Network, EJGE, Vol. 18.

[10]. Dilip Kumar Talukdar (2014), A Study of Correlation Between California Bearing Ratio (CBR) Value With Other Properties of Soil, International Journal of Emerging Technology and Advanced Engineering, Volume 4, Issue 1, January 2014).

[11]. Pradeep Muley, P. K. Jain (2013), Betterment and prediction of CBR of stone dust mixed poor soils, Proceedings of Indian Geotechnical Conference December 22-24, 2013, IIT Roorkee.
[12]. IS: 2720 (Part I), Indian standard method of test for soils. Preparation of dry soil sample for various soil, Bureau of Indian standards, New Delhi.

[13]. IS: 2720 (Part II), Indian standard method of test for soils. Determination of water content, Bureau of Indian standards, New Delhi.

[14]. IS: 2720 (Part III), Indian standard method of test for soils Determination of specific gravity, Bureau of Indian standards, New Delhi.

[15]. IS: 2720 (Part IV) Indian standard method of test for soils grain size analysis, Bureau of Indian standards, New Delhi.

[16]. IS: 2720 (Part V) Indian standard method of test for soils, Determination of liquid and plastic limit, Bureau of Indian standards, New Delhi.

[17]. IS: 2720 (Part VII) Indian standard method of test for soils, Determination of water content /dry density relation using list compaction, Bureau of Indian standards, New Delhi.

\section{BIOGRAPHIES}

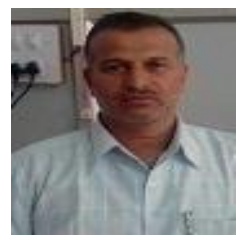

Dr P G Rakaraddi, $\mathrm{He}$ is presently working as a Professor in Civil engineering department, Basaveshwara Engineering college Bagalkot, Karnataka. He had post graduate in IIT Karagpur. And also he got $\mathrm{PhD}$ in Soil Dynamics from IISc Bangalore.

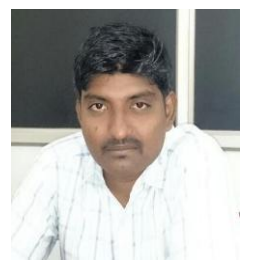

Vijay Gomarsi, Pursuing Post Graduation in geotechnical engineering at Basaveshwara Engineering College Bagalkot, Karnataka. 